\title{
CINDER-7: An Interim Report for Users
}

\author{
by
}

T. R. England

R. Wilczynski*

N. L. Whittemore

"Bettis Atomic Power Laboratory, West Mifflin, PA 15122.

UC-32 and UC.80

Reporting Date: February 1975

Issued: April 1975 
Work supported by the Division of Reactor Research and Development, U.S. Energy Research and Development Administration.

Printed in the Uniled Slatee of America. Available trom National Tochnical iniormation Service

US Department o! Commerce

$$
\begin{aligned}
& 5285 \text { Port Royal Road } \\
& \text { Springtield, VA } 22151
\end{aligned}
$$

Price: Prinled Copy $\mathbf{4 0 0}$ Microtiche $\$ 2.25$

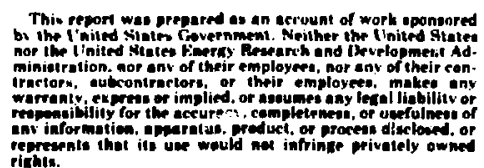

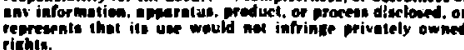


CINDER-7: AN INTERIM REPORT FOR USERS

by

T. R. England, R. Wliczynsk1, and N. L. Whitcemore

\section{ABSTRACT}

CINDER, a general nuclide depletion and fission-product code, has been reprogramed to utllize improved data handling subroutines, fmprove roundoff control, and Incorporate new calculational features such as a gamma spectra subroutine. The new coding uses a dynamic storage, varlable dimensioning, and a free-form Input format. The format is not compatible with earlier versions of CINDER. This report describes the format, Its bases, and some of its extended features.

\section{INTRODUCTION}

CINDER $^{1,2}$ is a generalized code that computes

the temporal composition of coupled nuclides in a

time-dependent flux envfronment. The nuclides can be coupled in any sequential mixture of radioactive decay types and neutron or other particle reactions. A neutron flux is normally used. The flux or fisston power, nuclide parameters, couplings which form nuclide chains, etc., can be specified by the user. The code also computes the concentration of coupled fission products generated by fission in fuel chains. Varfous quantities related to the nuclide densities, such as absorption bulld-up, fuel depletion, decay heating, activity and decay spectra are also computed.

Verstons of the basic code or its derivatives have been in use for more than 10 years. Since the code's inception, the quantity of basic nuclide data has greatly increased; for example, the ENDF/B-IV flles contain neutron absorption and decay parameter data for 824 nuclides classed as fission products. Many quantities which depend on the time-dependent concentration of nuclides can now be accurately computed, and a nuclide code is needed that is capable of ut1lizing the expanding data base as well as being suitable for the general user.

CINDER- 7 is a reprogrammed and extended version of the basic code and takes advantage of new coding cechniques which permit variable dimensioning, dynamic storage, and free-form input formats. It is capable of treating a wider variety of coupled nuclide problems for a wider class of users; data input is greatly simplified and less subject to error in input preparation. Output options have been extended.

Th1s report is essentially an interim manual for users and assumes famillarity with earlier versions or with Refs. 1 and 2. Although the basic concepts of CINDER remain unchanged, all input formats have necessarily changed because of the new coding bases outlined in the next section.

A large part of six of the seven subroutines associated entirely with CINDER-7 was coded during 1970-72 wh1le two of the authors were employed at the Bettis Atomic Power Laboratory. During 1974-75, the initial plans were extended and completed. In addition, the original dependence of CINDER-7 on the Bett1s Environmental Package for $C D C$ computers ${ }^{3}$ was eliminated (see App. A). The version of CINDER discussed in this report is now free standing and in essentlally standard FORTRAN. The only portion that is nonstandard FORTRAN is already available on most major computers and is expected to become a FORTRAN standard in 197 .. 
Additional code changes are in propress to facilitate use of the expanded decay and absorption data in ENDF/B-IV. A detalled report will be prepared for the final code and data witen these are fully opera:ional. However, CINDER-7 is the current validated verston in use at LASL and is expected to remain in use for an indefinite period, It is more than sufficient for most users and is a considerable improvement over versions of CINDER in general circuiation.

All capabilities of earller versions are retalned and extended. Some of the new features are described briefly in this report, and the general capabllitles, such as a gamma spectra routine are described in Sec. III. Actual Improvements in coding, such as an 1mproved roundof $f$ control, are not discussed in detail here.

Because the input format of CINEER-7 is incompatibie with prior verstons, the prinary purpose of this report is to describe the new format for LASL users already acquainted with the basic code.

\section{I1. SUMMARY OF CODING BASES AND FEATURES}

CINDER-7 exploits and extends the FORTRAN-IV capability of varlable array dimensions. Durfing the execution of a code, all variables are not usually of a maximun slze at the same time. Several subroutines, originally developed at the Bettis Atomic Power Laboratory for other cocies, have been modifled and incorporated into CINDER. These permit a trade off of parts of a single, large array stored in blank common where they can be referenced by various FORTRAN subprograme. The dynamic storage is described in Ref. 3, and the original routines are avallable from the Argonne Code Center. Of the small number cf these subroutines actually used, most have been modified to remove much of the machine dependence as well as interdependence on the large number of subroutines in the tora? Bettis FORTRAN Environmental Package. The names of the subroutines, identified in App. B, have not been changed, and Ref. 3 should be consulted for their basic functions. These modified subroutines account for less than $0.1 \%$ of the non-CDC versions of CINDER and only $\sim 25 \%$ of the CDC version (APp. A).

The recoded CINDER-7 subroutines fully exploit the varlable array dimensions permitted by FORTRANIV. The recoding has reduced required Input data and, in addition to providing the dynamic storagte, It has reduced the storage required by earlier versions of CINDER. Several quantities previously required as input are now computed directly from other input data. The flexible storage has permitted the addition of new options. All data are now input using a generalized format-f ree conversion routine which greatly simplifies input preparation. Thts, combined with other coding, also reduces imput by elininating the need to input classes of data which arc unused in a particular case and some parameters which are zrro or unity for any particular nuclide.

\section{A. Summary of New Features}

1. All data are input using a card index which identifies the nuclide, data type(s), and chain. The card order is net important and only those cards that are needed from case to case need be supplied. If there are duplicate card indices, then the data following the last duplicated Index is used. Thus the user can readily replace or modify library data without, e.g., recourse to UPDATE.

2. Variable dimensions, dynamic storage, free input format, etc., are used as already described.

3. Hecause of the flexible storage, the number of input quantities is limited only by the size of the computer's memory. Flextble input includes the number of chains, nuclldes per chain, titne 1ncrements, and time-dependent quantities such as group fluxes, factors applied to fluxes and cross sections, and other quantities such as the number of decay energy groups, and nuclides in power that yleld products on fission.

4. The actual storage required for input data and computations is calculated and printed on the output.

5. Nuclide cross sections can be changed individually in any neutron group at any time step by specification of factors on one card serles. Other card series permit nonunity branching factors for decay or absorption per nuclide, sumnary calculations of the aggregate resonance integrals, and also an effective $2200 \mathrm{~m} / \mathrm{s}$ cross section.

6. Extra summary listings include an option to selactively group nuclides, such as noble gases or major absorbers; the output print for these groupings also includes the aggregate resonance integral.

7. The irradiation history can be specified per time step in terms of: 
(a) the group iluxes;

(b) group-4 flux and ratios of higher energy group fluxes to the fourth grouf, or

(c) the power and flu: ratios.

The $f$ luxes can also be madified as noted under 3, above.

8. Decay energies tvelghted by intensities can be input in up to 100 groups of arbitrary width, or energles and intensitles cin be stored by nuclide and the user can specify the desired group structure. Current1y, stored ENDF/B-IV juclide data are appropriate for photoneutron production from ${ }^{9} \mathrm{Be}$ and ${ }^{2} \mathrm{~h}$, and the decay information pristed includes gammas per fission and per second for each nuclide and decay group.

9. The number and type o: chains and the number of nuclides in each chain are now computed automatically.

10. Several new print optlous per time step and rime-step sumnaries are avallaisle along with new punch options, as will be noted in Sec. III.

11. Decay heating (MeV/s and hev/fission) is calculated per nuclide and decay group per time step; aggregate values, summed over a11 nuclides per decay group, are also printed.

12. The data in each card field is interpreted from context, as described in Sec. III.

As in earlier CINDER versions, CINDER-7 permits the user to adjust roundoff control parameters to match his computer word length and to specify other quantities such as the total energy per fission.

This version of CINDER has been teited only on CDC computers, but the subroutines have been further modified to work on all major computers without loss of any feature (see App. A).

III. INPUT FORMAT FOR CINDER-7

\section{A. User Notes}

1. The following pages specify 21 card, or card Image, types each beginning with an index number which determines the type of data it carries. Cards are of the form index, $A, x_{1}, x_{2}, N_{1}, \ldots$, where $X$ denotes a real number, $N$ denotes integers and, when present, A denotes an alphanumertc. This notation is used for clarfty; the code actually interprets the fleid or data type from context, is explained later in this sectlon. A field consists of all entries between comnas. (See Sec. III-C for a sample input listing.)

2. Any card can be continued by placing a plus (+) sign as the first nonblank character.

3. In addition to the sperified card types, a title card can be entered. This begins with an equals $\Leftrightarrow$ sign as the first nonblank character. The last such card found is used as the title.

4. Comment cards can be Interspersed with data as desired. These begin with an asterisk $(*)$ as the first nonblank character, and are'printed in a card listing at the leginning of each output print but are not otherwise used.

5. The last cari of a case has a period (.) or negative integer as the first nonblank character.

6. Except for the pertod card, the cards can be entered in random order. Cards following the period card are ignored.

7. If two or more cards have identical indices, the data on the last card found are used. This is also a redundancy check; data on duplicate card indices (including field continuarions) are stored only for the last duplicate. Similarly, data on a card can be deleted by inserting a card having only the card index.

8. Most of the data cards described in this section are optional, but at least one of the followIng card types and the period card should appear in al1 cases: 1000001, 20TTTT, I'TCCCNN, 2TCCCNN.

9. Blank cards are 1gnored.

10. Any fleld can be repeated by having as its first nonblank character the slash (/), a repeat integer, and (/) preceding the fleld, 1.e., /N/.10+10 repeats the $.10+10$ fleld $\mathrm{N}$ times.

11. The cards are scanned from left to right and each fleld is examined for the characters,+- , $., 0,1,2,3,4,5,6,7,8,9$, and blank. If any character is not one of these, the field is assumed to be nonnumeric, or Hollerith.

12. The card index, or first character, can begin in any colunn. Leading blanks are 1gnored. All blanks are ignored in numeric fields; leading and cralling blanks are 1gnored in Hollerith flelds, However, Hollerith flelds may be spectified by enclosure in parentheses, ( ), In which case all blanks are retained. Any character except the dollar ( $\$$ ) sign may be included inside the parentheses. In numeric flelds, a fleld containing only blanks is con- 
verted to integer-zero. A field containing only a decimal point is converted as a real zero. In real fields the plus (t) sign is optional and discarded. The exponent is also optional if the dectmal point is included; the decimal point is optional if the exponent is included and in such event the decimal is assumed to be to the left of the first nonblank chatacter. For real fields, the following are all equivalent to $10^{-3}: 0.01-1,01-1, .001$. Leading zeros in an exponent or integer ffeld are 1gnored and, if a decimal point is embedded in a real field, leading zeros are ignored. The $E$ in real flelds, e.g., 0.01E-1, should not be used.

13. A card is assumed to have 80 culumns, but can be delimited by using the dollar (\$) sign. This also eliminates the data on any continuation card(s). 14. The following limits are arbitrary and can readily be changed:

Decay energies can be input in up to 101 groups; output prints label the first group as $B$ decay and the remainder as $\gamma$ decay. The actual group structure is arbitrary but is fixed by the user's lfbrary. $A$ second decay routine pernits $\gamma$ "IIne" data (energles and intensittes) to be stored and the group structure is speciffed for each run by an input card which lists the destred decay energy bounds.

Up to nine yield sets can be specified, but these can be used for any fissionable nuclide any number of times, for example, the user can specify that ${ }^{238} \mathrm{U}$ y 1 elds be used for ${ }^{238} \mathrm{U},{ }^{240} \mathrm{Pu}$, etc.

a sample input for a simple problem is provided In Sec. III-C.

Appendix A cescribes a slight varlation in input required for a version which is essentfally machine-1ndependent. The following card image description applies to CDC computers.

B. Input Card Types

The card types (card 1mages) described in this section need not be entered in order. For the convenfence of the user, card descriptions are lisfed in the Eollowing order (any card described here as Card 2 through Card 21 need not be present if it has zero data values).

\begin{tabular}{|c|c|}
\hline ORDER & CARD INDLX ${ }^{*}$ \\
\hline 1 & 100001 \\
\hline 2 & 20TTTT \\
\hline 3 & $1 \mathrm{TCCCNN}$ \\
\hline 4 & $2 \mathrm{TCCCNN}$ \\
\hline 5 & $3 T C C C N N$ \\
\hline 6 & $4 \mathrm{CCCNN}$ \\
\hline 7 & $5 \mathrm{TCCCNN}$ \\
\hline 8 & $7 \mathrm{TCCCNN}$ \\
\hline 9 & 100008 \\
\hline 10 & 100009 \\
\hline 11 & 8CCCFS \\
\hline 12 & 9TCCCNN \\
\hline 13 & 901 \\
\hline 14 & $1 \mathrm{JJSS}$ \\
\hline 15 & 100002 \\
\hline 16 & 2ТТТГ \\
\hline 17 & 1 \\
\hline 18 & 2 \\
\hline 19 & 3 \\
\hline 20 & 4 \\
\hline 21 & 5 \\
\hline
\end{tabular}

\section{Contro1 Card. Card 10001}

$100001, \mathrm{x}_{1}, \mathrm{x}_{2}, \mathrm{~N}_{1}, \mathrm{x}_{3}, \mathrm{x}_{4}, \mathrm{x}_{5}, \mathrm{~N}_{2}$

$x_{1}=$ Group- 4 spectrum or shielding factor. $x_{1}$ multiplles all group -4 cross sections except those given individual factors on card serles 5 TCCCNN.

If this factor is not the same for all time steps, specify 0.0 and input time-dependent values on time card series 20TTTT,

$x_{2}=$ Joules/fission (K, Eq. 3, Ref. 1) (for reference, $200 \mathrm{MeV}=0.32042 \times 10^{-10}$ ).

$\mathrm{N}_{1}=1-$ print: Contribution to (nuclide $\mathrm{X}$ ) from (nuclide $Y$ ) and preceding nuclides in chain ( $Z$ ) set to 0 (see Sec. $2 v$, Ref. 1).

$=0$ : this flag is not printed.

$T$ denotes a depletion or fuel chain $(T=1)$ or a fisston product chain $(T=2)$.

TTTT denotes a time-step number.

CCC denotes a chain sequence number beginning with 1 for $T=1$, and $T=2$ type chains.

Ni denotes the nuclide sequence in each chain.

$F, S, J J$, and SS are defined on the card type descriptions.

Unless otherwise speciffed, TCCCNN and the nuclide ID are used throughont the code as a cross reference to the input data library. 
$\mathrm{x}_{3}=$ Coupling criterion. Check against near zero divisors from $B$ and $\Delta i$. If zero, blank, or negative, $10^{-12}$ is used (see criterion 14, Ref. 1). Here $B \equiv \lambda+\sum_{g P} \sigma \phi .^{*}$

$x_{4}=$ Roundoff criterion. If zero, blark, or negative, $10^{-12}$ is used (see criterion 13, Ref. 1).

$x_{5}=$ If greater than 0.0 , then print option 3 on the time card series, 20TTT, will print only data for those nuclides having decay energles (MeV/s) exceeding $x_{5}$ percent of the total decay energy. If $x_{5}=0.0$, only the (nonredundant) nuclides are printed. If a small positive value is given, only radioactive nuclide data are printed, etc.

$N_{2}=0, \phi_{4}$ : Specifled on series 20TTTT (flux groups 1 to 3 are ratios to group 4 ).

1: Power is specified instead of $\phi_{4}$.

2: $\phi^{\prime} s$ are specified instead of racios.

2. Time Card Series. Cards 20TTTT

20TTTT, $x_{1}, x_{2}, x_{3}, x_{4}, N_{1}, N_{2}, x_{5}, x_{6}$

TTTT $=$ The time-step number. If the sime values are

to be used for a series of time steps, TTTT

is the number of the last time step in the series (e.g., a sinjile card, 20100, would use the $X$ values for all time steps from the last specifled time card through time step 100).

$x_{1}=$ Time-step length in hours.

$x_{2}=\phi_{1} / \phi_{4}$

$x_{3}=\phi_{2} / \phi_{4} \quad$ Fast-to-group-4 flux ratios

$x^{3}=2 \phi^{4} \quad$ (or $\phi$ 's if $N_{2}=2 \mathrm{con}$ card 100001).

$x_{4}=\phi_{3} / \phi_{4}$

$N_{1}=0$ : Onit the fission product print this time step (TS).

1: Full print this TS.

2: Delete all print this TS.

3: Print selected decay energies (1isting of nuclides in sum having a total MeV/s exceeding the percent, $x_{5}$, on control card).

4: Print all depletion chain information and all fission product information except the macroscopic absorption data.

5: Print information for all depletion chain nuclides and only those fission product nuclides in sum ( $N 1=1$ on card 1TCCCNN).

\footnotetext{
* The coupling criteria are flagged, but the code now automatically adjusts parameters to permit computations to continue. Here, $B$ denotes the total destruction rate per nuclide, including any shielding and flux adjustment factors.
}

$N_{2}=0$ : (Option to be added later.)

$\mathrm{x}_{5}=$ Either $\phi_{4}\left(\mathrm{n} / \mathrm{cm}^{2}-\mathrm{s}\right)$ or power density $\left(\mathrm{W} / \mathrm{cm}^{3}\right)$, depending on option specified on control card 1001001.

$x_{6}=$ Spectrum or shielding factor for each time step. $x_{6}$ multiplies all group 4 cross sections except those given individual factors on card serles 5TCCCNN. If $x_{1}$ on the control card (100001) is not equal to $0.0, x_{6}$ is ignored and therefore may be onitted.

3. Number Density and Nuclide Library, Card SEIies 1. Cards 1TCCCNN

1 TCCCNN, $A_{1}, X_{1}, X_{2}, N_{1}, N_{2}$

$T=1$ : Denotes a depletion or fuel chain.

$T=2$ : Denotes a fission product chain.

CCC $=$ The nuclide chain sequence.

$\mathrm{NN}=$ The nurlide sequence in the chain.

$A_{1}=$ Nuclide identification - alphabetic and/or numeric information such as U235, U238, etc.

$x_{1}=$ Initial number density (atoms/barn-cm).

$x_{2}=\lambda$ : Radioactive decay constant $\left(s^{-1}\right)$.

$\mathrm{N}_{1}=1$ : Include this nuclide in total absorption, barns/fission, disintegration rate summations, etc.

0 . Omit this nuclide in sumations.

$\mathrm{N}_{2}=$ Type of coupling to next nuclide.

1: Last nuclide in chain (no coupling).

2: Radloactive decay $(Y=\lambda)$.

3: Total absorption cross $\operatorname{section}\left(\gamma=A^{a}\right)$. $^{+}$

4: Cafture cross section $\left(\gamma=A^{a}-A^{f}\right)$.

4. Microscopic Absorption Cross Section Library, Card Series 2. Cards 2TCCCNN

2TCCCNN, $x_{1}, x_{2}, x_{3}, x_{4}$

$\left.\begin{array}{l}x_{1} \\ x_{2} \\ x_{3} \\ x_{4}\end{array}\right\}$

Total nuclide microscopic absorption cross sections (barns) in each energy group. $\neq$

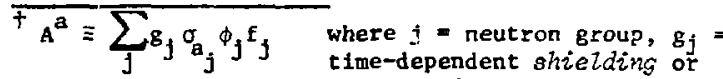
spectrum factor, $f_{j}=t$ ime-

dependent flux factor, $f$ and $g$ are 1.0 unless specifled otherwise on cards 2 TTTT or 5 TCCCNN. The $g_{j}$ factors are also applied to the fisaton cross sections to compute, e.g., $\mathrm{A}^{\mathrm{f}}$.

Card series 7TCCCNN is used to insert all nonunity branching factors which are applied to the $\gamma$ defined by the expressions under $\mathrm{N}_{2}$.

\# CINDER-7 presently permits one to four neutron groups. This is being changed to permlt an arbitrary number of groups. 
5. Microscopic Fission Cross Section Library. Card Series 3. Cards 3TCCCNN

3TCCCNN, $x_{1}, x_{2}, x_{3}, x_{4}$

$x_{1}$

$x_{2}=$ Total nuclide microscoptc fission cross

$\left.x_{3}\right\}=$ sections (barns) in each energy group.

$x_{4}$

6. Inttial Fission and Number Density Card Series. + (optional) Cards 4 CCCNN

$4 \operatorname{CCSNN}, \mathrm{x}_{2}, \mathrm{x}_{2}$

$x_{1}=$ Inttial ftssion denstty (fission/barn-cm).

$x_{2}=$ Initial number density to be used in "fuel-

fraction" calculation (atoms/barn-cm). This

need not be the same value as $x_{1}$ in card se-

ries 1 TCCCNN.

Supply this card only if card 100002 is pres-

ent, and then only for the fissile nuclides included in the power calculation. The $T$ is omicted in the card number because this serles is used on $1 y$ for depletion chain nuclides.

If there are no fissionable nuclides included in power, supply some value for $x_{1}$ to prevent a zero in the barns/fission calculations.

\section{Shielding Factor Card Series. (Optiona1) Cards} STCCCNN

$5 \operatorname{TCCNN}, x_{1}, x_{2}, x_{3}, \ldots, x_{N T}$

$T$ = 1: Depletion chain; group 1 shielding factor.

2: Fission product chain; group 1 shielding factor.

3: Depletion chain; group 2 shielding factor.

4: Fission product chatn; group 2 shielding factor.

5: Depletion chatn; group 3 shielding factor.

6: Fissics product chatn; group 3 shielding factor.

7: Depletion chain; group 4 snielding factor.

8: Fission product chain; group 4 shielding factor.

CCC $=$ The nuclide chatn.

*All nuclides, including fission products, can have a cross section specified here. Card 100008 specifies which nuclides are in power and contribute to fission product ylelds; in effect, card $10008 \mathrm{de-}$ rermines whether the cross sections specifled here are actual fission cross sections. Otherwise, this card is used to provide an exact representation of $(n, y)$ activations where a single branching fraction is adequate (see series TTCCCNN).

This spectal purpose card should not be confused with card 1 TCCCNN.
NN = The nuclide in the chath.

$x_{N T}=$ Shielding factor multiplying cross sections of this nuclide for time step or expansion NT.

If more than one card is needed for a nuclide, replace the card number by + on subsequent cards. If $N$ consecutive time-step factors are the same, $/ N / X_{N T}$ may be used.

The group -4 factor overrides any specifled valwe of $x_{6}$ on time series cards, 20TTTT, and $x_{1}$ on the control card, 100001 .

8. Branching Factor Card Serles. (Opt1ona 1) Cards $7 \mathrm{TCCCNN}$

7TCCCNN, $X$

$x=a$ : The frattion of total spectfied coupling (decay ir absorption) to a daughter nuclide (if card is not supplied, $X=1.0$ ).

In decay heat calculations where even the shortest lived nuclides are important and where multiple branches are the rule rather than the exception, a conventent new feature is the ability to sperify this branching factor, $\alpha$, $\alpha$ multiplies the coupling factor $\left(\lambda\right.$ or $\left.\sum_{g} \sigma \phi\right)$, producing the direct deughter nuclide in a linear chain (depletion or fission proditct). It does not directly affect any other computation, such as $\lambda N$. Note that in the case of neutron capture, unless all group cross sections divide in the same proportion, a single $\alpha$ factor cannot be used. However, the practice of using fictitious fission cross sections on card series 3TCCCNN and type 4 coupling is precise and conventent.

Example: $7200203, .942+0$

The $0.942 \mathrm{f}$ actor is applied to $A, A^{a}$, or $\left(A^{a}-\right.$ $A$ ) depending on the type of coupling specified for the third nuclide of fission product chain two.

The next three card descriptions (100008, 100009, 8CCCFS) are supplied if a nuclide is to be included In the power calculation.

9. Depletion Chain Nucl1des in Power. Card 10008 $100008, \mathrm{~N}_{1}, \mathrm{~N}_{2}, \mathrm{~N}_{3}, \ldots, \mathrm{N}_{1}$

$N_{j}=$ The nuclide to be included in the power calcu-

lation (Eq. 3, Ref. 1). $\mathrm{N}_{\mathrm{j}}$ is a five-digit fixed point number corresponding to CCCNN on the depletion chain Number Density and Nuclide Library Card Series, 1TCCCNN.

NOTE: Yleld fractions, even if zero, must be supplied for all fissile nuclides included in the power calculation, as noted for sertes 100009 and 8CCCFs. Example: $100008,00101,00102,00203,00204$. 
This example specifies that nuclides in power are the first nuclide in the first chain, the second nuclide in the first chain, the third nuclide in the second chain, etc.

10. Yield Deck Assignments. Card 100009

$100009, N_{1}, N_{2}, N_{3}, \ldots, N_{j}$

$N_{j}=$ The $F$ on card series 8CCCFS. Tells which yield deck ldentifled by $F$ corresponds to which nuclide $\left(N_{j}\right.$ on card 100008).

Example: $100009,1,3,3,2$ (refer to example on card 100008).

The ylelds in deck 1 are to be used for nuclide

1, depletion chatn 1. The ylelds in deck 3 are to be used for nuclide 2, depletion chain 1. The yields In deck 3 are to be used for nuclide 3, depletion chain 2. The ylelds in deck 2 are to be used for nuclide 4, depletion chain 2.

11. Yle1d Card Series. Cards 8CCCFS

$8 \operatorname{CcCFS}, \mathrm{Y}_{1}, \mathrm{Y}_{2}, \mathrm{Y}_{3}, \ldots, \mathrm{Y}_{\mathrm{NN}}$

CCC $=$ The fission product chain number

$\mathrm{F}=$ The depletion nuclide in power (each $F$ actual1y designates a deck). $F=1$ to 9.

$\mathrm{S} \quad=$ Sequence number (if more than one card is needed for a chain).

$Y_{N N}=$ The yield fraction (not percent) for nuclide Nh in fission product chain CCC.

Example: $800111, .1-3, .2-3,8-3$

$800211, .4-3, .5-3$

$80: 311, .6-3, .7-3$

$800121, .8-3,121.9-3$

-

$805321, .1-2, .2-2$

$800131, / 3 / 0.0$

$800231, .3-2, .4-2$

$800331, / 3 / .5-2, .6-2$

•

$802731, / 10 / .7-2, .8-2$

-

$805331, / 2 / .9-2$
1-3 1s the yield for nuclide 1 , fission product chain 1

.6-2 is the yield for nuclide 4, fisston product chain 3

.7-2 1s the yield for nuclide 10 , fission product chain 27

.2-2 is the yield for nuclide 2, fission product chain 53 .

NOTE: The first card of each input $y$ teld deck must the present even if all the values on it are equal to zero.

12. Energy Card Series. (Optional) Cards 9TCCCMN $\operatorname{9TCCCNN}, x_{1}, x_{2}, x_{3}, \ldots, x_{N}$ $x_{1}=E^{e}$, beca energy per decay in MeV.

$X_{N}=$ The energy per decay in $N$ energy groups. These can be arbitrary in the sense of energy range per group, type of decay, and energy units per decay. But corresponding ta expected usage, the program output labels the first group as a $B$ and the remaining groups as $\gamma$-decay energles. The output print includes a summation over the groups $2-\mathrm{N}$ per nuclide in addition to aggregate summations over al1 $\mathrm{N}$ groups.

13. r-Spectra Energy Band Card.* (Opt1ona1) Card 901

$901, x_{1}, x_{2}, x_{3}, \ldots, x_{n}$

$X_{N}=N$ energy values defining $N-1$ decay broups (group energy hounds) of arbitrary width: $x_{N}-1<X_{g} \leq X_{N}$, where $X_{g}$ denotes all $Y$ energies appearing in group $N$.

\footnotetext{
*The listed nuclides have $\gamma$ energies, intensities, and $\beta^{-}$end-point energies in data statements. The user must still specify nuclide chains and all other chatn data. The presence of the 901 card forces the code to look up the spectral data when one or more of the above ID's as listed occurs in a chain. This option should not be used when the 9TCCCNN
} card(s) is present.

These 32 nuclides are the only $f$ issign products having $\gamma$ energies above the ${ }^{9} \mathrm{Be}$ and ${ }^{2} \mathrm{H}(Y, N)$ threshold and $\tau_{y_{s}} \geqslant 15 \mathrm{~min}$ (above $1.67 \mathrm{MeV}$ ). A chain set in which they appear and ENDF/B-IV data are available.

Energy bounds are assumed to be in MeV.

Data for ather nuclides cin be stored in the SPEC $f$ routine.

At present, the output print is formatted for ip to 101 groups, but this can be increased if desired. 
If only the following list of nuclides is of Interest, chis card may be used in place of the Energy Card Series, 9TCCCNN.

$\begin{array}{rrrrr}\text { BR0840 } & \text { RH1060 } & \text { LA1400 } & \text { TC1040 } & \text { LA1430 } \\ \text { KR0870 } & \text { AG1120 } & \text { LA1410 } & \text { SN12SO } & \text { PR1460 } \\ \text { KR0880 } & \text { TE1311 } & \text { LA1420 } & \text { SB1290 } & \\ \text { RB0880 } & \text { I1320 } & \text { PR1440 } & \text { SB1310 } & \\ \text { Y0900 } & \text { I1340 } & \text { RB0890 } & \text { TE1331 } & \\ \text { Y0920 } & \text { I1350 } & \text { Y0940 } & \text { TE: 330 } & \\ \text { Y0930 } & \text { CS1380 } & \text { Y0950 } & \text { BA1410 } & \\ \text { ZR0970 } & & \text { NB0980 } & & \end{array}$

14. Extra Summary List1ngs Card. (Optional) Cards IJJSS

IJJSS , $\mathrm{N}_{1}, \mathrm{~N}_{2}, \ldots, \mathrm{N}_{1}$

$J J=A$ number designaring a group of nuclides $\left(\mathbb{N}_{1}\right.$, $\mathrm{N}_{2}, \ldots, \mathrm{N}_{\mathrm{i}}$ ) to be summed and 1 isted as a separate summary output. JJ can go from 01-99.

$\mathrm{SS}=$ Sequence number.

$N_{i}=A$ nuclide to be included in the sum of nuclides in group $\mathrm{JJ}$. $\mathrm{N}_{1}$ is a six-digit, fixed point number corresponding to TCCCNN on the Number Densty and Nuclide Library Card Series, ITCCCNN. The barns/fission for groups 1, 2, 3, and 4 and the number densicy are summed over all nuclides, $N_{1}$, Input per grouf $J J$ and listed by tIme step as a separate sumary. Resonance integrals are also included in this summary.

Example: 10101, 204204, 204502, 204602.

Nuclide 4 in chain 42

Nuclide 2 in chain 45

Nuclide 2 in chatn 46

These nucildes can be, for example, all ${ }^{135}$ Xe.

15. Continuation Card. (Optiona1) Card 100002

$100002, x_{1}, x_{2}, x_{3}, x_{4}$

Initial values of the following quantities can be

supplied:

$x_{1}=$ Elapsed time.

$x_{2}=$ Thermal flux $t$ ime $\left(\mathrm{n} / \mathrm{cm}^{2}\right)$.

$x_{3}=$ Integrated power $(W-s)$.

$\mathrm{x}_{4}=$ Integrated neutron absorption $\left(\mathrm{n} / \mathrm{cm}^{3}\right)$.

Any of the above quantities may be zero. This

card does not refer to a restart of a previous prob-

lem. It simply permits specification of initial

values of the quantities noted, which are otherwise set to zero inftially.

16. Time-Dependent Flux Factor Card. (Optional) Cards 2TTTT

2TTTT, $x_{1}, x_{2}, x_{3}, x_{4}$

TTTT $=$ The time-step number. If the same values are to be used for a series of time steps, TTTT
Is the number of the last tirae step in the

series.

$x_{1}=$ Factor on $\Phi_{1}$.

$x_{2}=$ Factor on $\Phi_{2}$.

$x_{3}=$ Factor on $\Phi_{3}$.

$\mathrm{x}_{4}=$ Factor on $\Phi_{4}$.

The number of these cards must be less than or equal to the number of time cards.

(These factors provide an additional degree of freedom in modifying neutron absorption In addition to the spectrum and shielding factors which are applled to the cross sections on serles 20TTTT and STCCCNN,)

17. Punched output for plots. (Optional) Card 1 $1, N_{1}, N_{2}, M_{1}, M_{2}, \ldots, M_{3}$

$N_{1}=$ The number assigned to the curve on the graph $\left(N_{1}=1\right.$ to 9$)$.

$N_{2}=1:$ Filapsed time is the abscissa.

2: Accumulated fission density is the abscissa.

$M_{f}=1$ : Punch fuel fraction for the nuclide specified on Card 5 .

2: Punch resonance integral (RI).

3: Punch $2200 \mathrm{~m} / \mathrm{s} \sigma$.

4: Purich $\sigma$ effective.

The M's are position-dependent in that the value of $j$ designates the graph number.

Example: $1,3,1,4,1,2$.

This set of curves is the third set on the graphs to be plotted.

Elapsed time will be punched on card sertes 101.

$\sigma$ effective w1ll be punched on card series 10302.

Fuel fraction will be punched on card serles 20302.

Resonance integral will be punched on card series 30301.

18. Punched Output of Summary Data. (Opciona1) Card 2

2,1

This card enables the user to obtain three subsets of punched output. Each set of punched data is preceded by a header card labeling the punched colutans. The entire set is sequentially numbered except for the header cards. Each subset, useful for different purposes, contains some punches redundant with the other sets. 


\section{PUNCH SET 1}

\begin{tabular}{|c|c|c|}
\hline Format & Columns & Data \\
\hline $6 \mathrm{x}$ & $1-6$ & Blank \\
\hline 13 & $7-9$ & Tin.z-step number \\
\hline $2 X$ & $10-11$ & Blank \\
\hline F14.8 & $12-25$ & TS diacrement (h) \\
\hline $2 X$ & $26-27$ & Blank \\
\hline F14.6 & $18-41$ & Accumulated time (h) \\
\hline $2 x$ & $42-43$ & Blank \\
\hline E12.6 & $44-55$ & Fission density (fissions/barn-cm) \\
\hline $2 \mathrm{x}$ & $56-57$ & Blank \\
\hline E] 2.6 & $58-69$ & $\begin{array}{l}\text { Accumulated fission density (fis- } \\
\text { sion/barn-cm) }\end{array}$ \\
\hline $3 \mathrm{x}$ & $70-72$ & Blank \\
\hline IS & $23-80$ & Sequent1al card number \\
\hline \multicolumn{3}{|c|}{ PUNCH SET 2} \\
\hline $6 \mathrm{x}$ & $1-6$ & Blank \\
\hline $\mathbf{I}$ & $7-8$ & Time-step number \\
\hline$F 14.8$ & $9-22$ & IS increment $(h)$ \\
\hline F14.6 & $23-36$ & Accumulated time (h) \\
\hline E12.5 & $37-48$ & Total $B$ energy rate $(\mathrm{MeV} / \mathrm{s})$ \\
\hline El?.5 & $49-60$ & Total $\gamma$ energy rate $(\mathrm{MeV} / \mathrm{s})$ \\
\hline E12.5 & $61-72$ & Total $\beta+\gamma$ energy rate $(\mathrm{MeV} / \mathrm{s})$ \\
\hline 18 & $73-80$ & $\begin{array}{l}\text { Sequentir } 1 \text { card numbers (contin- } \\
\text { ued from SET } 1 \text { ) }\end{array}$ \\
\hline
\end{tabular}

PUNCH SET 3

Same as SET 2, except etiergy rates are in MeV/ fission.

All punched data appear in the CINDER output. summary.

19. Resonance Integral Group Lethargies. * (Optiona1) Card 3

$3, x_{1}, x_{2}, x_{3}, x_{4}$

$\left.x_{1}\right)$

$x_{2}=$ The values for $k_{1}$ (1ethargies) in the reso-

$\left.x_{3}\right\}$ nance integral calculation (card type 5 )

$x_{4}^{3}$

If this card is not input, the following values are used:

$\ell_{1}=2.5$

$\ell_{2}=5.0$

$\ell_{3}=9.088399$

$\ell_{4}=0.0$.
20. Parameters for Calculation of Aggregate Resonance Integral and $2200 \mathrm{~m} / \mathrm{s}$ Cross Sect $10 \mathrm{a}$. (0ptiunal) card 4

$4, x_{1}, x_{2}, x_{3}, x_{4}$

$\left.\begin{array}{l}x_{1} \\ x_{2} \\ x_{3} \\ x_{4}\end{array}\right\}=$

The values of $g$ used In the resorance integral and $2200 \mathrm{~m} / \mathrm{s}$ cross section calculations (see card type 5).

If this card is not input, all values of $g$ are 1.0 .

21. Extra Sumary Print and Spectra Conversion Card. (Optional) Card 5

5, A, X

$A=$ The alphanumeric $D D$ of the fuel fraction destred to be stored over time and printed in the summary.

$x=$ The factor used for the conversion of $\hat{j}_{\text {eff }}$ (defined below) to other spectra. $X$ is normally zero.

Rescnance integral $=\sum_{i=1}^{4} \hat{\ell}_{i} \cdot \frac{\hat{\mathrm{Q}}_{i}}{\mathrm{~g}_{1}}$ per energy group $i$

where $\ell_{1}=$ input on card 3

$g_{1}=$ irput on card 4

$\theta_{f}=$ total/barns/fission.

$2200 \mathrm{~m} / \mathrm{s}$ sigma $=\frac{\hat{\theta}_{4}}{\mathrm{~g}_{4}}$

Sigma eff

$$
=\frac{\partial_{4}+\sum_{i=1} \frac{\phi_{1}}{\phi_{4}} \cdot \frac{\hat{\sigma}_{1}}{g_{i}}}{g_{4}}\left(1.0-x \cdot \frac{\hat{\sigma}_{3}}{\Phi_{4}}\right) .
$$

When $X=0, \sigma_{\text {eff }}$ is an effective $2200 \mathrm{~m} / \mathrm{s}$ barns/ fission, i,e., total reaction rate $=5_{4} \hat{\theta}_{\text {eff }} \phi_{4}=$ $\sum_{1=1}^{4} B_{1} \theta_{1} \phi_{1}$.

The caret $\left[{ }^{n}\right]$ denotes barns per fission.

C. Sample Input for CINDER-7

The following input sample spectfies:

2 depletion chains with 5 nuclides in the first chain and 6 in the second.

2 fission product chains with 2 and 1 nuclides, respectively.

4 time steps with zero power at rS 2 and 4 and $2.86 \times 10^{5} \mathrm{~W}$ at TS 1 and 3. Time increments are $51.84,164.16,326.4$, and $33.6 \mathrm{~h}$.

Ratios of the 3 fast flux groups to the group -4 flux are 5.06, 7.95, and 5.98 during the two TS at power.
${ }^{*}$ RI is printed on the output summary, not after each detailed time-step print. 
9 nuclides are in power (out of the 11 in the depletion chains). All nuclides except ${ }^{232}$ Th and ${ }^{23} \mathrm{~Pa}$ in the first depletion chain contribute to dgm gregate sumations (of barns/fission, macroscopic absorption, decay heating, etc.).
The 5TCCCNN series cards specify factors which alter the cross sections at various time steps.

Cards beginning with (*) are optional comment cards; these are discarded by the code before execution. Data storage for this sample equals $364_{10}$; $628_{10}$ are additionally required for calculations.

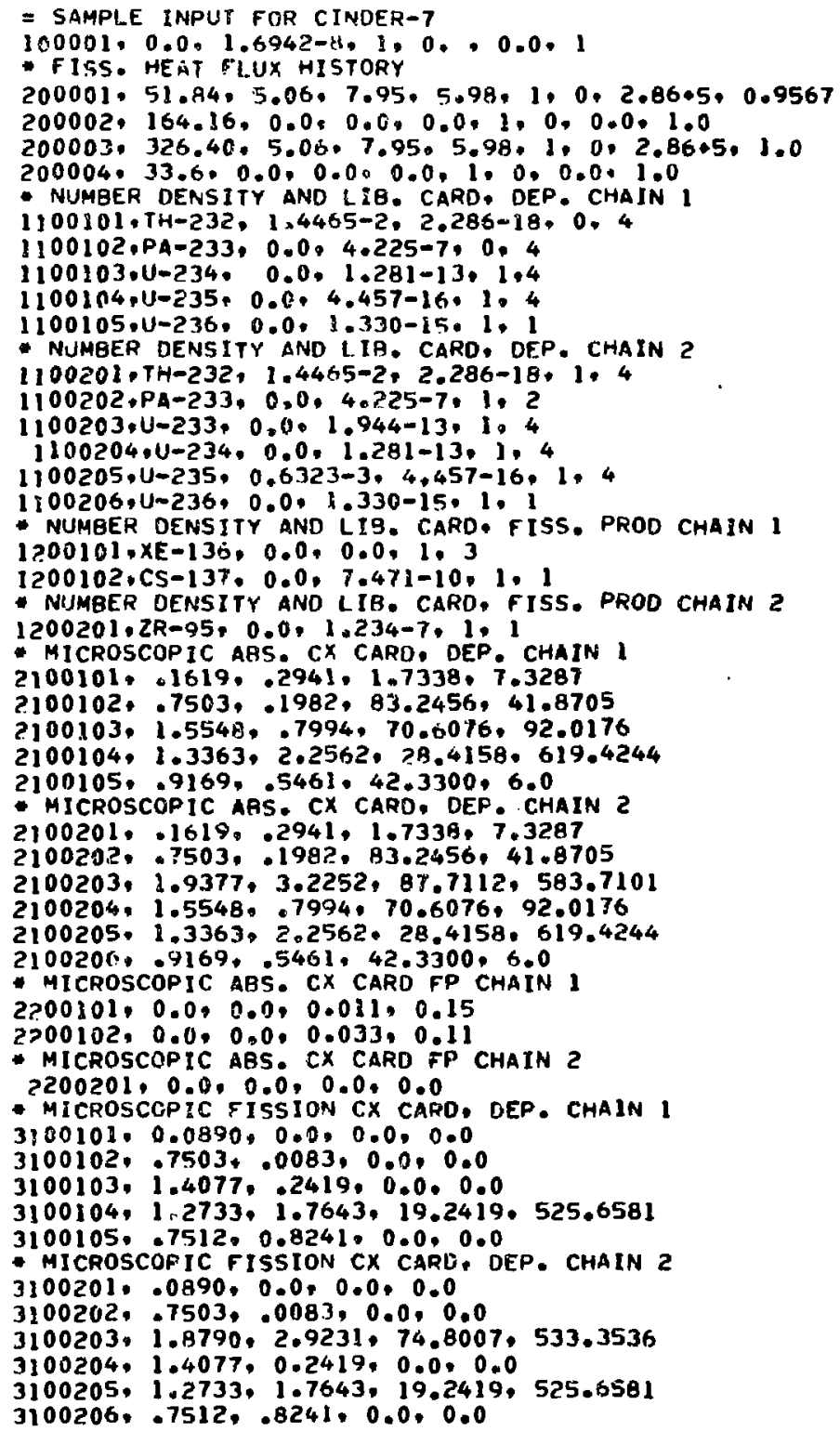




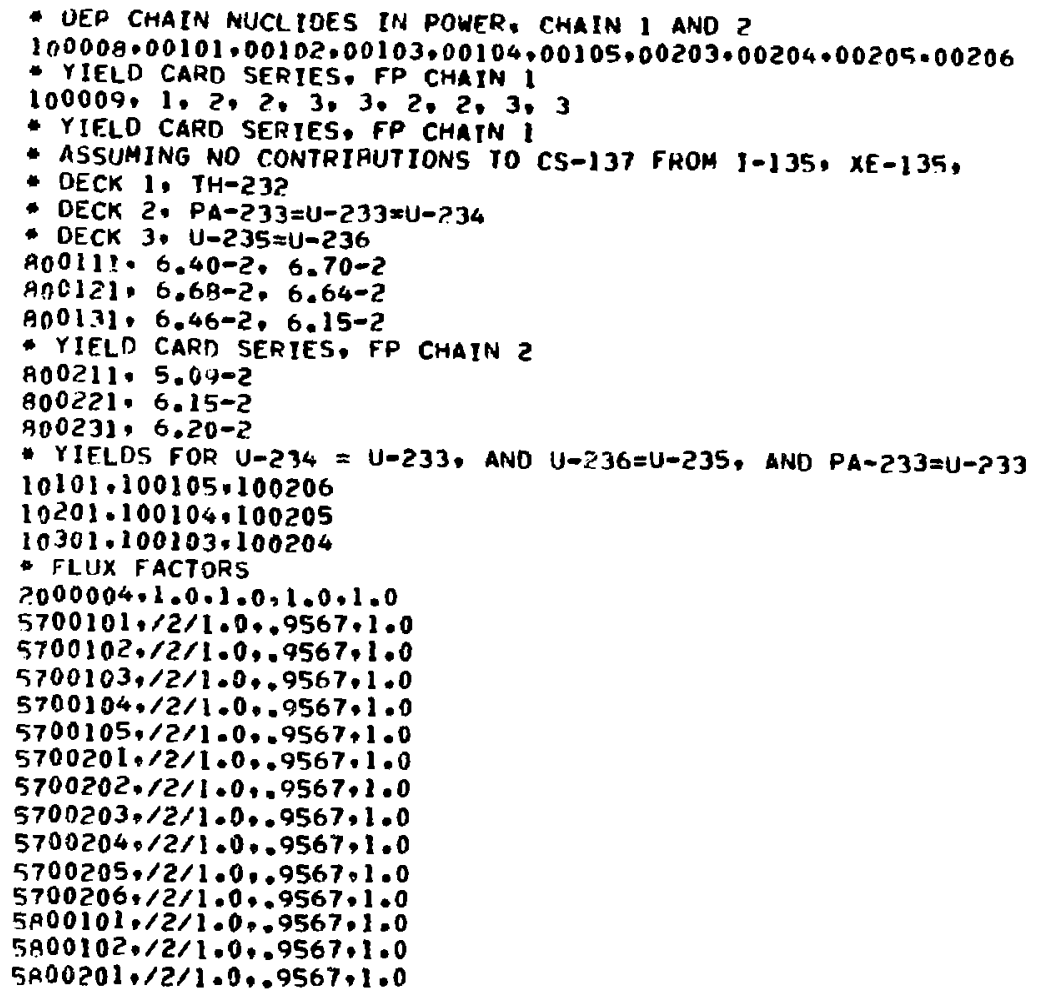

\section{ACKNOWLEDGMENTS}

The need to update the CINDER coding was In1tlally recognized and largely supported by the Nuclear Design and Analysis section of the Light Water Breeder Project of the Betits Atomic Power Laboratory (BAPL), and ia particuler by managers G. H. Conley and H. F. Raab. The completion of CINDER-7 was a cooperative BAPL-IASL effort, as is the contirued coding and data library development; however, the interim version of CINDER described in this report and the one in use at BAPL will differ in detall, as will the final codes and data librarles.
A major task confronting non-Bettis users was to divorce the new CINDER routines from the BAPL Environmental Package, as described in App. A, while retaining some of the excellent concepts and some coding developed by the Bettis programming staff. In this and other respects the assistance of $\mathrm{K}$. $\mathrm{H}$. Witte, LASl, Group $(-3)$ was Invaluable. During the last year, the completion of CINDER-7 and the further development of CINDER has been Independently encouraged by D. R. Harris (LASL, Group $\mathrm{I}-2$ ) and N. Steen (BAPL).

\section{APPERDiX A}

STANDARD FORTRAN AND CDC VERSLONS OF CINDER-7

The subroutines abstracted from Ref. 3 were very tinterdependent, many were unnecessary to CINDER, some were in the obsolete ASCENT language, and some interacted with the I/O and the dayille.
To create a free-standing version of CINDER of reasonable size, we inftially abstracted about 1800 of the 22000 cards in the input package, and elimInated the obsolete ASCENT language. We later ellm- 
Inated 9 subroutines unnecessary to CINDER by eliminating calls and modifying the CINDER and remaining linput package routines as necessary. Some modifications were also needed to remove communfation with the dayfile, etc. The 19 subroutines remaining are relatively small, totaliag $\sim 1300$ cards (In CDC verston). The most important functions of these routines (Ref. 3) have been retained. The input specifications of Sec. III refer to these modifications, and this verston of the code is specifically designed for CDC computers. Machine dependence for this version is based primarily on the 60-bit word length, but statements in Ref. 3 regarding defendence st 111 apply.

STANDARD FORTRAN VERSION

An even larger effort was made to produce all CINDER subroutines in standard FORTRAN which would be operational on most large computers without loss of the features described in the body of this report. Here the major problem was with a format-free tnput. However, a version which is essentially standard FORTRAN was finally coded and tested.

Toelve of the 19 remaining rout ines from the modified Bettis input package were eliminated and the remainder recoded. This part of the code now totals $\sim 200$ cards. The exposition in the body of this report also applies to the general FORTRAN version using the following input conventions:

Card I - Hollerith title card

Data cards in any order

Last card - any negative integer.

The remaining machine and compller dependencies are summarized in Table $A-I$.
TABLE A-I

MACHINE AND COMPILER DEPENDENCLES OF CINDER-? Necessary changes:

1. Program card.

2. Size of arrays in blank common and varlables IASIZE and NCDSIz defining thetr stze.

3. Subroutine INTTAP, Set I to the integer value of your input unit.

4. Subroutine DUTTAP. Set $L$ to the integer value of your output unft.

5. Subroutine INP. Change the free-format read statement (11st-directed read) INFUT (IN) NC (NCARD+1), B, For IBM 360 it would be: RFAD (IN, *) NC(NCARD+1),B. This is nonstandard. CDC and RCA compilers do not have free-form reads.

Nonstandard Features:

1. Implied do loop notation in data statements. Some compllers allow this and some allow an array name without subscript. All major FORTRAN compliers* allow one or the other.

2. Mxed-mode arithmetic (Inceger and real). All major FORTRAN compilers allow this.

3. Punch statemunts. A1l major FURTRAN compilers allow this.

4. " $A$ " type formats repend on word and b1t size of each mashine. (NOTE: Precede A fields with NH, 1.e., 4HU235.)

* Major FORTRAN compilers are those of CDC, GE, Honeywe11, IBM, Univac, XDS, Burroughs, and DEC.

\section{APPENDIX B}

LIST OF SUBROUTINES IN CINDER-?

There are two versions of CINDER-7 subroutines. Subroutines listed in Table B-I apply to the standard FC RTRAN version as described in App. A. It will work with major FORTRAN compilers (CDC, GE, Honeywe11, IBM, Univec, XDS, Burroughs, and DEC). As noted in App. A, it reauires only ininor changes from machine to machine. The subtoutines listed in Table B-II are used specifically for CDC compilers that do not permit the nonstandard FORTRAN statements required for the free-format read. This version is currently being used for informal communication with BAPL, but iuth versions are operationa) at LASL. 
TABLE B-I

STANDARD FORTRAN VERSION OF CINDER-7

Subroutine OcEgl Lengeh

(CINDER Subroutines)

$\begin{array}{lr}\text { CINDR } & 204 \\ \text { RDI } & 5210 \\ \text { WRTISP } & 1757 \\ & \\ \text { CALCUL } & 4720 \\ \text { TALER } & 4563 \\ \text { SURRY } & 2365\end{array}$

(Data Storage and

Interpretat Ion Subroutines)

INTI'AP

OUT:AP

INP

14

LINI:

74

MOVER

LINE

343

FINISH

TABLE B-II

CDC 6600 and 7600 VERSION OF CIRDER-7 Subroutine Octal Length

(CINDER Subroutines)

$\begin{array}{lr}\text { CINDR } & 213 \\ \text { DR1 } & 4646 \\ \text { WRTINP } & 1564 \\ \text { CALCUL } & 4630 \\ & \\ \text { SPECT } & 2416 \\ \text { TALEN } & 2306 \\ \text { SURY } & 2142\end{array}$

(Daca Storage and

Interpretation Subroutines)

$\begin{array}{lr}\text { FINISH } & 66 \\ \text { ØUTTAP } & 14 \\ \text { INTTAP } & 14 \\ \text { LINES } & 13 \\ \text { INP } & 301 \\ & \\ \text { JNP2 } & 512 \\ \text { LINK } & 133 \\ \text { IITLE } & 43 \\ \text { CARDS } & 1774 \\ \text { INPFIX } & 132 \\ & \\ \text { INPFLT } & 357 \\ \text { INPSEP } & 76 \\ \text { INPCKN } & 33 \\ \text { INPWCH } & 107 \\ \text { PACK } & 10 \\ & \\ \text { UNPACK } & 10 \\ \text { INPRINT } & 60 \\ \text { INPHOL } & 224 \\ \text { NODER } & 274 \\ & \end{array}$

DATA STORAGE

In efther code, essentiglly all data storage is In a single blank-common array. The size is currently set at $30000_{10}$. This is specified in the CINDER routine as IBSIZ. The code output print includes a atatement giving the actual storage used and the additional btorage required for running each case. If the net storage exceeds the specified size of IBSIZ, the user 16 informed by an output print and the case is not run.

BEFERENCES

1. T. R. England, "CIADER - A One-Point Depletion and Flasion Product Program," Bettis Atomic Power Laboratory report WAPD-TM-334(Rev) (1964).

2. T. R. England, "An Investigation of Fiasion Product Behavior and Decay Heating in Nuclear Reactors," Thesis, Universtey of Wisconsin, 1969 (Untv. Microftlms oräer No. 70-12, 727).

3. C. J. Pfelfer, "CDC-6600 FoRTRAN Frogramming Bettis Environmental Report," Bettis Atomic Power Laboratory report WAPD-TM-668 (1967). 